\title{
INTERDISCIPLINARIDADE E QUESTÕES DISCURSIVAS: UMA ALTERNATIVA
}

\section{Dioni Maria dos Santos Paz}

O objetivo deste artigo é polemizar sobre dois assuntos que considero de suma importância: a interdisciplinaridade e as questões discursivas. Às vésperas do ano 2001, é de nos questionarmos como a prática escolar e acadêmica, atualmente fechadas em cadeias disciplinares responsáveis por uma aprendizagem limitada, irá sobreviver em face da era da globalização.

A questão que aqui colocamos consiste em pensar na possibilidade de se romper no campo educacional com o "peso" do paradigma disciplinar, sinônimo de ciência, e passar a assumir como científica sua interdisciplinaridade.

Segundo SANTOS (1992), interdisciplinaridade é a colaboração entre várias disciplinas, através de programas de pesquisa, visando à integração e $/$ ou à coordenação de conceitos, métodos e conclusões, com reciprocidade nas trocas, o que implica mútuo enriquecimento. Nesse sentido, a habilidade em utilizar teorias em comunhão com outros campos do saber pode ser um momento de crescimento, um lugar dinâmico e dialético, no qual, através da prática interdisciplinar, se constroem objetos de conhecimentos específicos e gerais. Para tal, é urgente um diálogo entre as várias disciplinas, deixando um pouco de lado a disciplinaridade, isto é, a exploração apenas de um domínio de saber determinado e homogêneo de estudo, no qual estão presentes tanto a formulação e a reformulação permanente de conhecimento como o "estabelecimento de fronteiras".

$\mathrm{Na}$ interdisciplinaridade afirma-se a atividade de transmissão e a difusão de vários conhecimentos, criando-se condições que tornarão possíveis novas formas de produção desses saberes. É um momento didático em que a transdisciplinaridade se estabelece como básica. Segundo SANTOS (op.cit.), transdisciplinaridade é entendida enquanto reconhecimento da interdependência dos vários aspectos da realidade, em que interações ou reciprocidades entre várias disciplinas estão situadas no interior de um sistema de relações "sem fronteiras" estáveis entre si.

Nessa perspectiva, fica aberto um espaço para aplicação de metodologias que visem a um contínuo processo de produção de 
conhecimentos interligados. Espaço esse onde os pressupostos disciplinar, interdisciplinar e transdisciplinar se articulam, assumindo, cada um, em determinado momento, uma "liderança" contextual, isto é, momento em que as diferentes disciplinas atuariam como alicerces do saber, a fim de dinamizar currículos do ensino fundamental, médio e superior.

JAMATI (1992) aceita a abordagem de um mesmo campo por uma equipe interdisciplinar, desde que haja a distinção nas respostas. Segundo ela, cada disciplina pode contribuir para a explicação de um subconjunto limitado de fatos que se encaixam no problema de outra disciplina. Então, é necessário que o professor de uma área tenha conhecimento aprofundado dos conceitos específicos da sua área, porém também possa se abrir a outros campos de conhecimento, buscando as relações de seu conhecimento com os diversos campos de saber.

Uma alternativa, talvez eficiente para o amadurecimento e o enriquecimento global do professor e do aluno, seja a aplicação de questões discursivas, nas diferentes instâncias do ensino, privilegiando o bom uso da língua materna. Mas como elaborar as questões e avaliar os resultados? Seria um trabalho conjunto entre os professores das disciplinas implicadas?

A idéia de questões interdisciplinares e/ou discursivas exigiria uma grande mudança nas didáticas e nas metodologias aplicadas pelos professores. Todavia, cada uma das disciplinas deveria metodologicamente delimitar um aspecto particular do campo de conhecimento, para permitir aos professores um consenso sobre os conceitos exigidos.

Por outro lado, no plano prático, a educação exige uma postura interdisciplinar, uma vez que tem de levar em conta todos os elementos que compõem o universo da existência humana. Então, usar um método interdisciplinar, em sua "verdade complexa", decorre do esforço mútuo de algumas disciplinas.

Essa divagação me é necessária à medida em que temos conhecimento de que, em quase todas as escolas brasileiras, as provas são em forma de questões objetivas e disciplinares. São raros os professores que ousam articular questões discursivas e interdisciplinares. Uma das razões, sabemos bem, deve-se ao excessivo número de aulas e de alunos de cada professor. No entanto, imaginamos ser possível, uma vez que outra, questões descritivas, narrativas ou dissertativas em biologia, química, física, história, matemática, geografia, literatura, língua portuguesa, entre outras disciplinas.

Com essa alternativa, a nossa língua materna estaria sendo 
bastante valorizada no âmbito estudantil, pois não podemos esquecer que estamos próximos a países que falam a língua espanhola, a qual está chegando com força total nas escolas e nos cursinhos brasileiros por causa do Mercosul. E nós sabemos que o domínio de um país pode começar pelo domínio de um idioma ou pela perda de sua identidade como nação.

Essa proposta exige competências que reúnam habilidades e capacidades numa estreita relação umas com as outras. Para que isso ocorra, é necessário um vínculo entre a preparação e a execução de exercícios. O que o professor precisa saber fazer é elaborar questões discursivas / interdisciplinares e avaliar as mesmas; enquanto o que o aluno precisa saber fazer é compreender no ato de ler e compor no ato de escrever. Devese lembrar sempre que o objetivo da aprendizagem é desenvolver a capacidade subjacente de interpretação do texto e reprodução do conhecimento.

No outro pólo da nossa proposta, vemos que a prática pedagógica convencional tem mostrado preferência pela direção oposta, isto é, questões objetivas e disciplinares. O princípio básico parece ser uma aderência à segregação ao invés da integração: "dividir para governar". Isso se deve porque os diferentes componentes da fórmula básica dos livros didáticos não possuem laços de intercâmbio entre as disciplinas. Assim, não é incomum encontrar resistência dos professores e dos alunos quanto à maneira de trabalhar a interdisciplinaridade e questões discursivas.

Parece-me, também, que a questão crucial é a grade curricular dos cursos de formação de professores. Uma saída para o problema seria contemplar as dimensões dos conteúdos, das metodologias e das relações situacionais, envolvendo várias disciplinas. Isso mostra a relação da tensão disciplinar I interdisciplinar com a concepção de construção cognitiva do conhecimento, mas conservando a idéia de disciplina, uma vez que devemos reconhecer nas disciplinas os elos materiais de ordenação dos caminhos a serem mapeados.

Para ilustrar tudo o que foi proposto, daremos um exemplo de questão que poderia ser usada pelo professor de química, física e / ou língua portuguesa.

Exercício 1

"Combine os seguintes grupos de frases de maneira que produzam enunciados apropriados:

a)Alguns líquidos servem de condutores de eletricidade.

Alguns líquidos se decompõem quando uma corrente elétrica os atravessa. 
b) O recipiente contém um eletrólito.

Neste processo, duas peças de metal são conectadas a uma bateria. num recipiente.

Neste processo, duas peças de metal são colocadas

c) Um eletrodo é conectado pólo positivo da bateria.

Um eletrodo é conectado ao pólo negativo da bateria.

Um eletrodo é chamado de catodo.

Um eletrodo é chamado de anodo.

d)Uma reação química ocorre.

A corrente é ligada.

A corrente atravessa o eletrólito.

Note-se ainda que, embora esse exercício exija esforço da habilidade de compor do aprendiz, isso não é feito sem propósito, mas sim com o objetivo de produzir enunciados significativos: ele é realizado como um aspecto necessário da escrita. As quatro frases em (c), por exemplo, podem ser combinadas de tal maneira que juntas componham o seguinte período:

"Um eletrodo, chamado de anodo, é conectado ao pólo negativo da bateria e o outro eletrodo, chamado de catodo, é conectado ao pólo positivo da bateria."

Mas, embora esse período esteja impecavelmente correto enquanto tal, ele não constitui um enunciado correto sobre anodos e catodos. Da mesma forma, é possível combinar a frase em (d) para que forme uma frase que seja correta mas cujo enunciado é impreciso:

"Quando ocorre uma reação química, a corrente é ligada e atravessa o eletrólito."

Esse exercício de transformação já encaminha bastante o aprendiz na direção do discurso oferecendo-lhe a oportunidade de utilizar os itens anafóricos como o "outro" em (c) e "ela" em (d). O próximo passo poderia levá-lo ainda mais adiante nessa direção, solicitando ao aprendiz que tome as frases que produziu e as combine com outras frases derivadas do texto original. Com essa atividade, o aprendiz chega a um segundo estágio do discurso que representa uma versão resumida do primeiro.

Exercício 2

Combine as frases seguintes com as frases que você escreveu no Exercício 1 para produzir um resumo do texto. Modifique as frases onde for necessário:

a)As peças de metal conectadas a uma bateria são 
conhecidas como eletrodos.

b) O processo pelo qual alguns líquidos se decompõem quando uma corrente elétrica os atravessa é chamado de eletrólise.

c)Os líquidos que se decompõem quando uma corrente elétrica os atravessa são conhecidos como eletrólitos.

d)A corrente passa de um eletrodo ao outro.

Um possível resultado dessas operações é o seguinte:

Discurso 2: Alguns líquidos que servem como condutores de eletricidade se decompõem quando uma corrente elétrica os atravessa. Alguns líquidos são conhecidos como eletrólitos e o processo é chamado de eletrólise. Nesse processo, duas peças de metal, conhecidas como eletrodos, são conectadas a uma bateria e colocadas num recipiente contendo um eletrólito. Um eletrodo, chamado de catodo, é conectado ao pólo negativo e o outro, denominado anodo, ao pólo positivo da bateria. Quando a corrente é ligada, ela atravessa o eletrólito de um eletrodo ao outro e uma reação química ocorre". (WIDDOWSON, 1991: 201203).

Naturalmente, essa não é a única construção possível. Outras versões podem ser efetuadas, pois é uma composição livre, mas deve estar condicionada ao propósito comunicativo. Na medida em que outros modelos de exercícios se diversificam, o aluno deve ser orientado até a produção de resumos, resenhas e paráfrases, entre outros, integrando, assim, habilidades e capacidades.

Portanto, estimados professores, colegas preocupados com o rumo da educação em nosso país, está na hora de nos unirmos em defesa de um ensino de qualidade que realmente capacite 0 aluno na hora de exercer uma profissão.

Importante é o fato de que cada uma disciplina saiba oferecer elementos suficientes, que, em conjunto com outras áreas intelectuais, produzam resultados enriquecedores para o aluno. Dessa forma, estaremos incentivando a transdisciplinaridade e a interdisciplinaridade como um novo paradigma na construção do saber.

Faço votos para que todos os envolvidos no processo ensinoaprendizagem busquem a pedagogia que alie responsabilidade e dedicação ao complexo ato de ensinar e formar cidadãos.

\section{BIBLIOGRAFIA:}


FRIGOTTO, Gaudêncio. "A interdisciplinaridade como necessidade e como problema nas ciências sociais". In: Educação e Realidade. Porto Alegre, 1993.

JAMATI, Isambert. "Ciência da educação: um plural importante quando se trata de pesquisa". In:Teoria e Educação, São Paulo, n.5, 1992.

LIBÂNEO, José C. Didática. São Paulo, Cortez, 1991.

SANTOS, Camilo. A Interdisciplinaridade na universidade: relevância e implicações. Educação Brasileira, Brasília, v.14, n.29, 1992.

WIDDOWSON, H.G. O ensino de línguas para a comunicação. Campinas.São Paulo: Pontes, 1991. 